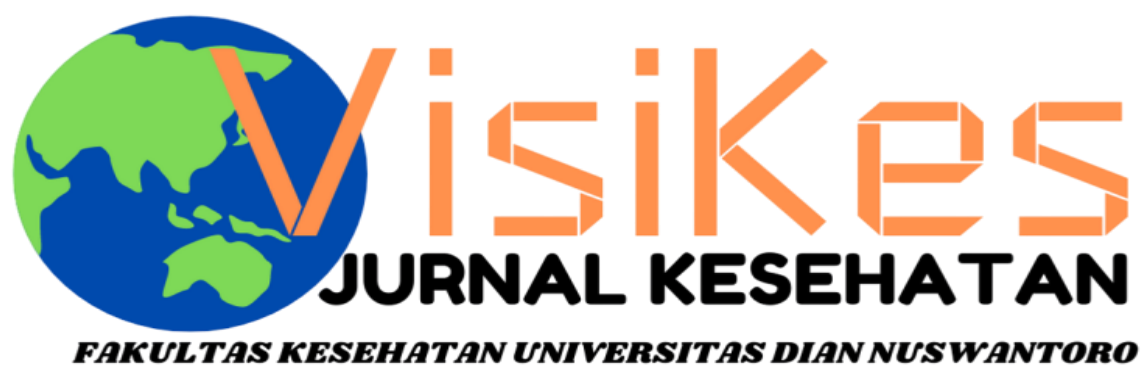

ISSN 1412-3746

FAKULTAS KESEHATAN UNIVERSITAS DIAN NUSWANTORO

Persepsi Mahasiswa Keperawatan Tentang Eskalasi Tenaga Perawat

Rendi Ariyanto Sinanto', Vivi Retno Intening ${ }^{2}$

Risiko kesehatan $\mathrm{Pb}$ dan $\mathrm{Hg}$ pada sayuran di desa Kopeng Kabupaten Semarang

Indira Casheila Anindityo ${ }^{1}$, Nur Endah Wahyuningsih ${ }^{2}$, Yusniar Hanani Darundiati ${ }^{3}$

Analisis Pelaksanaan Program Indonesia Sehat Dengan Pendekatan Keluarga (Pispk) Dalam Capaian Indeks Keluarga

Sehat Di Kabupaten Brebes Tahun 2020 Studi Pada Puskesmas Kluwut Kabupaten Brebes

Rizky Aprilianti Lestari ${ }^{1}$ dr. Antono Suryoputro ${ }^{1}$ Dr. dr. Apoina Kartini. M. Kes ${ }^{1}$

Disiplin Keselamatan dan Kesehatan Kerja melalui pemakaian alat pelindung diri di laboratorium kimia PT Sucofindo

Jakarta

Susan Endah Kartikasari ${ }^{1}$, Tatan Sukwika ${ }^{2}$

Perbedaan Pengetahuan Anemia dan Tablet Tambah Darah (TTD) Sebelum dan Sesudah Pendidikan Kesehatan Melalui

Media Video dan Aplikasi Quizlet

Devita Sari ${ }^{1}$, Gisely Vionalita ${ }^{2}$

Tingkat Pengetahuan Dan Perilaku Mahasiswi Mengenai Legalitas Dan Keamanan Kosmetik

Hani Sri Fitriani, Rizki Siti Nurfitria

Evaluasi Manajemen Dokumen Rekam Medis Di Filing Aktif Rumah Sakit Swasta Kabupaten Semarang

Bobby Anggara Laksana Putra ${ }^{1}$, Retno Astuti Setjaningsih ${ }^{2}$

Tingkat Pengetahuan Gizi Seimbang dan Profil Kesehatan Sopir Bus Antar Kota

Vilda Ana Veria Setyawati ${ }^{1}$, Bayu Yoni Setyo Nugroho ${ }^{1}$

Pengaruh Pengetahuan Dan Motivasi Kerja Terhadap Penerapan Early Warning Score System Di Rsup H Adam Malik Ita Riahna Pinem ${ }^{1}$, Zulfendri', Siti Saidah Nasution ${ }^{3}$

Analisis Penelusuran Masker Sebagai Protokol Kesehatan Saat Pandemi Covid-19 Di Indonesia: Studi Google Trends Ully Febra Kusuma ${ }^{1}$, Nurunnisa Arsyad ${ }^{2}$, Melissa Shalimar Lavinia ${ }^{3}$, Selvia Rahayu ${ }^{4}$, M. Khairul Kahfi , Rizma Adllia Syakurah ${ }^{6}$ Perilaku Hidup Bersih Dan Sehat (Phbs) Dengan Kejadian Sakit Pada Siswa Sekolah Dasar Di Kabupaten Banyumas Windri Lesmana Rubai ${ }^{1}$, Pramesthi Widya Hapsari', Katri Andirini Surijati ${ }^{3}$

Identifikasi Risiko Ganguan Muskuloskletal Pada Pekerja Percetakan Dengan Metode Nordic Body Map

Octavianus Hutapea ${ }^{1}$, Moch.Sahri', Rustam Basuki ${ }^{3}$

Literatur review: Implementasi Bauran Pemasaran 7P Terhadap Tingkat Kepuasan Pasien Di Rumah Sakit

Desi Natalia Marpaung ${ }^{1}$ Ernawaty $^{2}$ Diansanto Prayoga ${ }^{3}$ Syifa'ul Lailiyah $^{4}$

Kelengkapan Informasi Medis Untuk Mendukung Kodefikasi Penyakit Jantung Guna Mewujudkan Kualitas Data Informasi Medis Di Rumah Sakit Islam Sultan Agung Semarang

Dyah Ernawati ${ }^{1}$, Ratna Rifatul Ulya ${ }^{2}$, Arif Kurniadi ${ }^{3}$

Kajian Faktor Kendala Dokter Tidak Menggunakan Aplikasi Wifi Tb Di Kota Semarang

Arif Kurniadi', Evina Widianawati2, Dyah Ernawati ${ }^{3}$

Analisis Pelaksanaan Program Penanggulangan Tuberkulosis Paru Di Puskesmas Purwoyoso Kota Semarang

Nahari Ratu Cempaka Wilis ${ }^{1}$ Hardi Warsono ${ }^{2}$ M. Sakundarno Adi ${ }^{3}$

Hubungan Penggunaan Alat Pelindung Diri (Apd) Dengan Kadar Sgot Dan Sgpt Dalam Darah Pada Petani Padi

Iga Maliga, Rafi'ah

Faktor Risiko Kejadian Stunting Pada Balita di Wilayah Kerja Puskesmas Pandan Kabupaten Sintang

${ }^{1}$ Agustini Elisabet, ${ }^{2}$ Elvi Juliansyah

Peran Suami Dan Petugas Kesehatan Dengan Deteksi Dini Kanker Serviks

Christina Leasa, ${ }^{1}$ Mariene Wiwin Dolang

Analisis Penerapan Protokol Kesehatan terhadap Tingkat Kepatuhan Pada Pekerja informal Selama Pandemi Covid-19

MG Catur Yuantari ${ }^{1}$, Enny Rachmani ${ }^{2}$, Eti Rimawati ${ }^{1}$, Sri Handayani ${ }^{1}$, Edi Jaya Kusuma ${ }^{2}$

Peran Pengawas Minum Obat Dan Pendampingan Berobat Ulang Dengan Keberhasilan Pengobatan Tb Paru

Taswin $^{\left.1^{*}\right)}$, (zan $^{1)}$, Wahyuddin $^{1)}$, Dahmar ${ }^{1)}$

Faktor Determinan Sosial Dan Gambaran Kejadian Post Traumatic Syndrome Disorder (Ptsd) Pasca Banjir Di Dki Jakarta

Dan Bekasi Tahun 2020

Thresya Febrianti ${ }^{1}$, Nurfadhillah ${ }^{2}$, Mitha Nurhjanah ${ }^{3}$, Tiara Kautsa Aliefya ${ }^{4}$

Perbedaan Pola Makan Pada Balita Stunting Dan Tidak Stunting Di Kecamatan Teon Nila Serua (Tns) Kabupaten Maluku Tengah

Trixie Leunupun ${ }^{1}$, Ani Margawati' ${ }^{2}$ Annastasia Ediati ${ }^{3}$

Gambaran Pengelolaan Rekam Medis Rawat Inap Di Rsud Syekh Yusuf Kab. Gowa Tahun 2019

Zilfadhilah Arranury*, Surahmawati, Muhammad Rusmin, Tri Addya Karini, Dian Rezki Wijaya, Ranti Ekasari, Jihan Sulfitri

Analisis Risiko Kesehatan dalam Pemanfaatan Kemball Limbah Sludge Industri Makanan PT. X

Sri Slamet Mulyati ${ }^{1}$, Fajar Sihite ${ }^{2}$ 


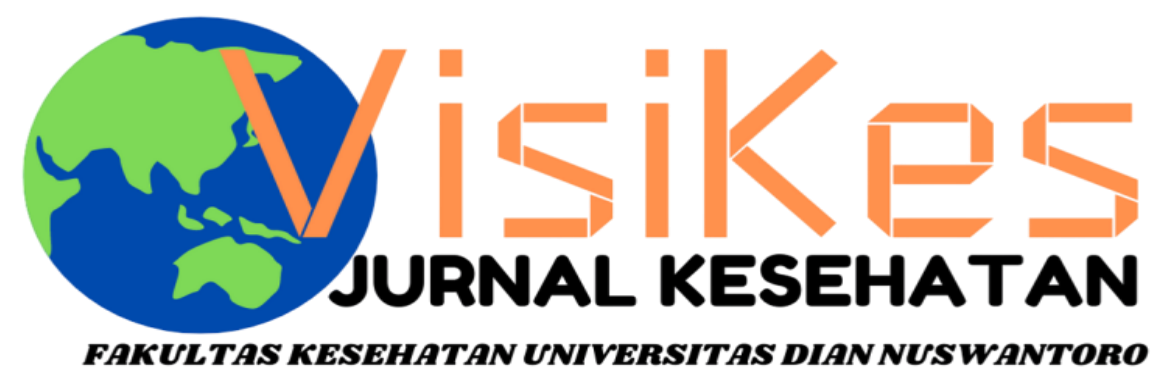

Volume 20, Nomor 1, April 2021

\section{Ketua Redaksi}

Dr. Drs. Slamet Isworo, M.Kes

\section{Penyunting}

Enny Rachmani, SKM, M.Kom, Ph.D

Fitria Wulandari, SKM, M.Kes

\section{Sekretariat}

Lice Sabata, SKM

Desain dan Layout

Puput Nur Fajri, SKM

\section{Alamat Redaksi}

Fakultas Kesehatan Universitas Dian Nuswantoro Jl. Nakula I No. 5-11 Semarang Telp/fax. (024) 3549948

email : visikes@fkes.dinus.ac.id

website $\quad$ : http://publikasi.dinus.ac.id/index.php/visikes/index

VisiKes diterbitkan mulai Maret 2002

Oleh Fakultas Kesehatan Universitas Dian Nuswantoro 


\title{
Faktor Determinan Sosial Dan Gambaran Kejadian Post Traumatic Syndrome Disorder (Ptsd) Pasca Banjir Di Dki Jakarta Dan Bekasi Tahun 2020
}

\author{
Thresya Febrianti ${ }^{1}$, Nurfadhillah², Mitha Nurhjanah ${ }^{3}$, Tiara Kautsa Aliefya ${ }^{4}$ \\ 1,2,3,4 Faculty of Public Health, Universitas Muhammadiyah Jakarta, Jl. K.H Ahmad Dahlan, Cirendeu, \\ East Ciputat, South Tangerang, Banten, Indonesia. 15419, email : thresya.febrianti@umj.ac.id
}

\begin{abstract}
This study aims to look at the prevalence of Post-Flood PTSD and to analyze the Social Determinants of the Risk of Post-Flood PTSD in Jakarta and Bekasi. Floods in the Greater Jakarta Area in February 2020 resulted in many losses such as casualties and damage to infrastructure. This research is able to answer the challenges in taking preventive measures for PTSD after the flood disaster. This research is an analytical study with a cross sectional study approach with a total sample of 100 people and selected by purposive sampling. The results will be analyzed bivariately. More than half the age of the respondents are in the adolescent age group (12-25 years) (65\%), are female (69\%), half of the respondents work $51 \%$, more than half of the respondents received low family support (51\%), received low peer support (50\%), did not receive volunteer support (66\%), did not receive the support of religious leaders (53\%). There is no relationship between respondent characteristics, family support, friends, relative volunteers and religious leaders.
\end{abstract}

Keywords: Post Traumatic Stress Disorder, Flood, mental health illness

\begin{abstract}
ABSTRAK
Penelitian ini bertujuan untuk melihat prevalensi kejadian PTSD Pasca Banjir dan menganalisis Faktor Determinan Sosial terhadap Risiko PTSD Pasca Banjir di Jakarta dan Bekasi. Kejadian Banjir di Wilayah Jabodetabek bulan Februari 2020 mengakibatkan banyak kerugian seperti korban jiwa dan kerusakan infrastruktur. Dampak psikologis yang sering terjadi pasca bencana salah satunya Post Traumatic Stress Disorder (PTSD) jika masalah ini tidak ditanggulangi akan berdampak pada kesehatan masyarakat di masa yang akan datang. Penelitian ini merupakan penelitian analitik dengan pendekatan cross sectional study dengan jumlah sampel sebanyak 100 orang dan dipilih secara purposive sampling. Hasil akan dianalisis bivariat. Lebih dari setengah usia responden berada pada kelompok usia remaja (12-25 tahun) (65\%), berjenis kelamin perempuan sebanyak $(69 \%)$, hanya $3 \%$ responden yang mengalami risiko PTSD pasca banjir, lebih dari setengah responden yang mendapat dukungan keluarga rendah (51\%), mendapat dukungan teman yang rendah (50\%), tidak mendapat dukungan relawan (66\%), tidak mendapat dukungan tokoh agama (53\%). Tidak terdapat hubungan dari krakteristik responden, dukungan keluarga, teman, tetngga relawan dan tokoh agama.
\end{abstract}

Kata kunci : Post Traumatic Stress Disorder, banjir, gangguan kesehatan mental

\section{PENDAHULUAN}

Bencana di Indonesia dalam kurun waktu 2009-2018 memiliki kecenderungan meningkat dari 1.246 kejadian tahun 2009 dan pada tahun 2018 mengalami peningkatan hampir 3 kali dengan rata-rata 12 kejdian bencana tiap harinya. Risiko kejadian bencana berdasarkan jenis bencana dari tahun 2009-
2018 paling banyak yaitu banjir (35\%), puting beliung (30\%), tanah longsor (23\%), kebakaran hutan dan lahan (5\%) ${ }^{(1)}$. BNPB mencatat sedikitnya ada 207 kejadian bencana yang terjadi di Indonesia berdasarkan rekapitulasi data hingga 21 Januari 2020. Jenis bencana yang mendominasi dengan jenis 
bencana hidrometeorologi seperti puting beliung dengan total kejadian 90 kejadian, banjir 67 kejadian, tanah longsor 45 kejadian, kebakaran hutan dan lahan 3 kejadian gelombang pasang sebanyak 2 kejadian (2).

Berdasarkan Data Badan

Penanggulangan Bencana Daerah (BPBD) Provinsi DKI Jakarta per 1 Januari 2020, sebanyak 60\% (157) kelurahan di Jakarta terkena dampak banjir. Kelurahan terdampak banjir terbanyak ada di Jakarta Timur yaitu sebesar $77 \%$, lalu diikuti oleh Jakarta Utara (74\%), Jakarta Barat (57\%), Jakarta Selatan (50\%) dan Jakarta Pusat (39\%). Sebanyak 36.445 warga yang terdampak mengungsi dengan pos pengungsi sebanyak 247 pos, selain itu terdapat 19 korban yang meninggal dunia, 15 diantaranya merupakan korban yang terdampak langsung seperti tersetrum dan hanyut. Kejadian banjir di awal tahun 2020 juga terjadi di 53 titik Kota Bekasi dan 32 titik di Kab. Bekasi. Laporan BPBD Kota Bekasi menyebutkan terdapat 149.537 orang (31.783 KK) Pengungsi, yang terdiri dari 49.716 anakanak, 68.038 dewasa dan 31.783 lansia. Warga mengungsi di kantor kelurahan, masjid, atau rumah warga yang aman dari banjir ${ }^{(3)}$.

Peristiwa bencana alam khususnya banjir memberikan dampak pada individu dan keluarga yaitu terganggunya masalah fisik dan psikis serta dampak lainnya yaitu menimbulkan kerugian dan penderitaan sehingga mempengaruhi aspek-aspek kehidupan baik lingkungan dan sosial ${ }^{(4)}$. Hasil survey menunjukkan setelah kejadian bencana sebagian besar populasi yang menjadi korban memiliki reaksi psikologis yang normal, sebanyak $15-20 \%$ akan mengalami gangguan mental ringan atau sedang yang merujuk kepada kondisi PTSD dan 3-4\% akan mengalami gangguan mental besar seperti depresi berat dan kecemasan tingkat tinggi (5). Faktor-faktor seperti sosiodemografi, latar belakang, karakteristik paparan lingkungan, dukungan sosial dan sifat kepribadian sebagai penyebab PTSD ${ }^{(6)}$.

Hasil penelitian yang sudah dilakukan di berbagai negara menjelaskan bahwa bencana banjir memberikan dampak psikososial bagi korban bencana, peristiwa tersebut memiliki pengaruh yang signifikan terhadap kesejahteraan manusia, hubungan dan kesehatan mental. Kejadian banjir dapat menimbulkan masalah sosial dan kesejahteraan dalam waktu yang lama ${ }^{(7)}$.

Kejadian banjir di wilayah Jabodetabek yang terjadi pada bulan Februari 2020 mengakibatkan banyak kerugian. Tidak hanya secara fisik namun dampak traumatis seperti PTSD menjadi permasalahan serius apabila tidak ditangani secara dini dan dapat menganggu proses kehidupan. Penelitian terkait PTSD Pasca banjir masih jarang dilakukan di Indonesia dan masih belum adanya data awal menilai dampak traumatis tersebut sehingga tujuan penelitian ini untuk melihat prevalensi risiko kejadian PTSD dan faktor determinan sosial yang mempengaruhi risiko kejadian PTSD Pasca Banjir di Jakarta dan Bekasi.

\section{METODE PENELITIAN}

Jenis penelitian yang dilakukan merupakan jenis penelitian analitik dengan pendekatan kuantitatif. Desain studi dalam 
penelitian ini adalah desain studi cross sectional. Penelitian dilakukan di wilayah DKI Jakarta dan Bekasi. Populasi dalam penelitian ini yaitu seluruh penduduk berusia $>15$ tahun dan tinggal tetap di wilayah DKI Jakarta dan Bekasi minimal 6 bulan sebelum bencana Banjir 2020. Jumlah sampel dalam penelitian sebanyak 100 orang setelah ditambahkan $10 \%$. Sampel dipilih secara accidental sampling.

Sumber data dalam penelitian adalah data primer yang dikumpulkan dengan menggunakan kuesioner dengan cara menyebarluaskan google form kepada responden berdasarkan kriteria inklusi. Kuesioner berisi tentang variabel dependen (kriteria PTSD yang terdiri dari 20 pertanyaan berdasarkan kriteria dalam DSM-V) dan variabel independen yang terdiri dari karakteristik responden (usia, jenis kelamin dan pekerjaan), dan variabel dukungan sosial yang terdiri dari dukungan keluarga, teman, tokoh agama, dan relawan. Analisis data yang digunakan dalam penelitian ini yaitu analisis univariat dan bivariat.

\section{HASIL}

Tabel 1. Gambaran Risiko Kejadian PTSD

\begin{tabular}{lcc}
\hline Risiko PTSD & Frekuensi & Persentase \\
\hline Berisiko & 3 & 3,0 \\
Tidak berisiko & 97 & 97,0 \\
\hline Total & 100 & 100,0 \\
\hline
\end{tabular}

Tabel 1 menunjukkan bahwa pada PTSD pasca enam bulan banjir di wilayah umumnya responden tidak memiliki risiko Jakarta dan Bekasi $(97,0 \%)$

\begin{tabular}{|c|c|c|}
\hline Karakteristik Responden & Frekuensi & Presentase \\
\hline \multicolumn{3}{|l|}{ Usia } \\
\hline - Remaja (12-25 tahun) & 65 & 65,0 \\
\hline - Dewasa (26-45 tahun) & 22 & 22,0 \\
\hline - Lansia (46-65 tahun) & 13 & 13,0 \\
\hline \multicolumn{3}{|l|}{ Jenis Kelamin } \\
\hline - Perempuan & 69 & 69,0 \\
\hline - Laki-laki & 31 & 31,0 \\
\hline \multicolumn{3}{|l|}{ Pekerjaan } \\
\hline - Bekerja & 51 & 51,0 \\
\hline - Tidak Bekerja & 49 & 49,0 \\
\hline
\end{tabular}

Tabel 2 didapatkan bahwa mayoritas usia responden berada pada kelompok usia remaja (12-25 tahun) sebanyak 65 orang (65\%). Berdasarkan jenis kelamin mayoritas responden adalah perempuan sebanyak 69 orang (69\%). Variabel status pekerjaann didapatkan bahwa status pekerjaan responden yang bekerja sebanyak 51 orang (51\%) dan yang tidak bekerja sebanyak 49 orang (49\%). 
Tabel 3. Hubungan Usia dengan Risiko PTSD

\begin{tabular}{llllll}
\hline Risiko PTSD & N & Mean & Stand. Deviasi & Stand. Error & $\boldsymbol{P}$ value \\
\hline Ya & 3 & 23,3 & 4,933 & 2,848 & 0,489 \\
Tidak & 97 & 28,38 & 12,511 & 1,270 & \\
\hline
\end{tabular}

Tabel 3 didapatkan rata-rata usia responden yang berisiko untuk PTSD adalah 23,3 tahun dengan standar deviasi 4,933 dan usia responden yang tidak berisiko untuk
PTSD adalah 28,38 dengan Standar deviasi 12,511. Dari hasil uji statistik didapatkan bahwa tidak ada perbedaan yang signifikan antara rata-rata usia dengan risiko PTSD.

Tabel 4. Hubungan Variabel Independen terhadap Risiko Kejadian PTSD Pasca Banjir Tahun 2020

\begin{tabular}{|c|c|c|c|c|c|c|}
\hline \multirow{3}{*}{ Variabel } & \multicolumn{4}{|c|}{ Risiko PTSD } & \multirow{3}{*}{ POR (95\%Cl) } & \multirow{3}{*}{ P-Value } \\
\hline & \multicolumn{2}{|c|}{ Berisiko } & \multicolumn{2}{|c|}{ Tidak } & & \\
\hline & $\mathbf{n}$ & $\%$ & $\mathbf{n}$ & $\%$ & & \\
\hline \multicolumn{7}{|l|}{ Jenis Kelamin } \\
\hline Laki-laki & 1 & 3,2 & 30 & 96,8 & \multirow{2}{*}{$\begin{array}{l}1,12 \\
(0,09-12,76)\end{array}$} & \multirow{2}{*}{1,00} \\
\hline Perempuan & 2 & 2,9 & 67 & 97,1 & & \\
\hline \multicolumn{7}{|l|}{ Pekerjaan } \\
\hline Bekerja & 1 & 2,0 & 50 & 98,0 & \multirow{2}{*}{$\begin{array}{l}0,47 \\
(0,04-5,13)\end{array}$} & \multirow[b]{2}{*}{0,61} \\
\hline Tidak Bekerja & 2 & 4,1 & 47 & 95,9 & & \\
\hline \multicolumn{7}{|c|}{ Dukungan Keluarga } \\
\hline Rendah & 1 & 2,0 & 50 & 98,0 & \multirow{2}{*}{$\begin{array}{l}0,47 \\
(0,04-5,36)\end{array}$} & \multirow{2}{*}{0,61} \\
\hline Tinggi & 2 & 4,1 & 47 & 95,9 & & \\
\hline \multicolumn{7}{|c|}{ Dukungan Relawan } \\
\hline Tidak & 1 & 1,5 & 65 & 98,5 & \multirow{2}{*}{$\begin{array}{l}0,25 \\
(0,02-2,81)\end{array}$} & \multirow[t]{2}{*}{0,27} \\
\hline $\mathrm{Ya}$ & 2 & 5,9 & 32 & 94,1 & & \\
\hline \multicolumn{7}{|c|}{ Dukungan Teman } \\
\hline Rendah & 0 & 0,0 & 50 & 100,0 & \multirow[b]{2}{*}{-} & \multirow{2}{*}{0,24} \\
\hline Tinggi & 3 & 6,0 & 47 & 94,0 & & \\
\hline \multicolumn{7}{|c|}{ Dukungan Tokoh Agama } \\
\hline Tidak & 0 & 0,0 & 47 & 100,0 & \multirow[t]{2}{*}{-} & \multirow[t]{2}{*}{0,25} \\
\hline $\mathrm{Ya}$ & 3 & 5,7 & 50 & 94,3 & & \\
\hline
\end{tabular}

Berdasarkan tabel 3 proporsi jenis kelamin yang berisiko untuk PTSD mayoritas perempuan sebayak 2 orang (2,9\%) dibandingkan dengan laki-laki sebanyak 1 orang $(3,2 \%)$. Hasil uji statistik didaparkan bahwa $p$ value 1,00 ( $p$ value $>0,05$ ), artinya tidak ada hubungan yang signifikan antara jenis kelamin dengan risiko PTSD. Proposi responden yang memiliki dukungan keluarga berisiko untuk PTSD mayoritas dukungan dengan kategori tinggi sebanyak 2 orang $(4,1 \%)$ dibandingkan dengan yang dukungan dengan kategori rendah sebanyak 1 orang $(2,0 \%)$. Hasil uji statistik didapatkan bahwa $p$ value 0,614 ( $p$ value $>0,05$ ), artinya tidak ada hubungan yang signifikan antara pekerjaan responden dengan risiko PTSD. Proposi responden yang memiliki dukungan teman berisiko untuk PTSD mayoritas dukungan dengan kategori tinggi sebanyak 3 orang 
(6,0\%). Hasil uji statistik didapatkan bahwa $p$ value 0,242 ( $p$ value $>0,05$ ), artinya tidak ada hubungan yang signifikan antara pekerjaan responden dengan risiko PTSD. Proposi responden yang memiliki dukungan relawan berisiko untuk PTSD mayoritas sebanyak 2 orang $(5,9 \%)$ dibandingkan dengan yang tidak memiliki dukungan sebanyak 1 orang $(1,5 \%)$. Hasil uji statistik didapatkan bahwa $p$ value 0,266 ( $p$ value $>0,05$ ), artinya tidak ada hubungan yang signifikan antara pekerjaan responden dengan risiko PTSD. Proposi responden yang memperoleh dukungan tokoh agama berisiko untuk PTSD mayoritas sebanyak 3 orang (5,7\%). Hasil uji statistik didapatkan bahwa $p$ value 0,245 ( $p$ value > $0,05)$, artinya tidak ada hubungan yang signifikan antara pekerjaan responden dengan risiko PTSD.

\section{PEMBAHASAN}

Hasil penelitian menunjukkan bahwa sebagian kecil responden memiliki risiko untuk mengalami kejadian PTSD pasca 6 bulan banjir di Jakarta dan Bekasi yaitu 3\%. Penelitian yang dilakukan di Kelurahan Rumbai juga menunjukkan bahwa $6,7 \%$ mengalami semua gejala PTSD ${ }^{(8)}$. Hasil penelitian yang dilakukan di India menunjukkan kejadian PTSD pasca bencana besar sangat bervariasi tergantung pada kejadian bencana tersebut. Studi yang dilakukan beberapa bulan setelah bencana menunjukkan terjadinya manifestasi kejiwaan yang lebih tinggi (9).

PTSD yang dialami oleh masyarakat yang menjadi korban bencana dapat berdampak terhadap terhambatnya aktivitas sosial, mengganggu kesehatan fisik dan mental para korban bencana ${ }^{(10)}$. Gejala-gejala PTSD yang dialami masyarakat pasca bencana bisa hilang timbul sepanjang hidup mereka, sehingga dapat mengganggu kualits hidup para korban bencana ${ }^{(11)}$.

Hasil analisis didapatkan bahwa tidak ada hubungan yang signifikan antara jenis kelamin dengan risiko PTSD. Sejalan dengan penilitian yang dilakukan oleh A. FontalbaNavas, et al (2017) tentang insiden dan faktor risiko pada PTSD di populasi yang terdampak banjir, didapatkan $p$ value sebesar 0,36 yang menjelaskan bahwa jenis kelamin bukan sebagai prediktor gejala PTSD ${ }^{(12)}$.

Namun penelitian sebelumnya yang dilakukan oleh Mohammad Amin Wani, et al (2016), menghasilkan data yang bertolak belakang. Dari hasil analisis dengan menggunakan uji independent t-test, membuktikan bahwa perempuan memiliki tingkat PTSD yang tinggi dibandingkan laki laki. Hasilnya menunjukkan perbedaan signifikan antara skor rata - rata subjek perempuan dan laki - laki. Skor rata - rata kelompok perempuan $(45,52)$ lebih dari nilai rata - rata kelompok laki - laki $(38,02)$. Rata rata, S.D, dan SEM perempuan dan laki - laki ditemukan [ $(\mathrm{M}=45,52$, S.D $=12,89$, SEM = 1,05), $(M=38,02, S \cdot D=11,73, \mathrm{SEM}=0,96)]$ masing - masing dan $t$ value $(5,27)$ dengan DF 298 yang ditemukan signifikan pada level signifikansi 0,01 ${ }^{(13)}$.

Hasil analisis hubungan Usia dengan Risiko PTSD didapatkan rata-rata usia responden yang berisiko untuk PTSD adalah 23,3 tahun dengan standar deviasi 4,933 dan 
usia responden yang tidak berisiko untuk PTSD adalah 28,38 dengan satndar deviasi 12,511. Dari hasil uji statistik didapatkan bahwa $p$ value 0,489 ( $p$ value $>0,05$ ), artinya tidak ada perbedaan yang signifikan antara rata-rata usia dengan risiko PTSD.

Pada penelitian yang telah dilakukan sebelumnya oleh Mohammad Amin Wani, et al (2016), ditemukan hasil yang sejalan dengan hasil bahwa remaja menunjukan tingkat PTSD yang lebih tinggi daripada orang dewasa, sebagai skor rata - rata mereka $(44,25)$ lebih dari skor rata - rata orang dewasa $(39,29)$ masing - masing. Demikian pula, rata - rata, S.D, SEM dan $t$-value remaja dan dewasa ditemukan $[(\mathrm{M}=44,25, \mathrm{~S} . \mathrm{D}=12,54$, $\mathrm{SEM}=$ 1,02), $(M=38,02, S \cdot D=11,734, \mathrm{SEM}=0,985)$ dan $(t$-value $=3.40, \mathrm{df} 298)$ yang lebih dari nilai tabulasi pada tingkat signifikansi 0,01 . Hasil penelitian menunjukan korelasi negatif antara PTSD dan usia $(-0,193){ }^{(13)}$. Hasil penelitian yang dilakukan di Hunan, China juga menunjukkan bahwa tidak ada hubungan antara usia dengan Kejadian PTSD ( $p$ value $=$ 0,093) $)^{(14)}$.

Berdasarkan pekerjaan, responden yang berisiko untuk PTSD mayoritas tidak bekerja sebanyak 2 orang (4,1\%) dibandingkan dengan yang bekerja sebanyak 1 orang (2,0\%). Hasil uji statistik didapatkan bahwa $p$ value 0,614 ( $p$ value $>0,05$ ), artinya tidak ada hubungan yang signifikan antara pekerjaan responden dengan risiko PTSD. Berdasarkan penelitian yang telah dilakukan oleh Surwaningsih et al., (2019) di Garut, Jawa barat, didapatkan bahwa hubungan pekerjaan terhadap risiko PTSD dengan metode Chi
Square, menunjukkan data yaiu: 1) Buruh Petani, dengan jumlah frekuensi 3 dan persentase $6,7 \%$, 2) PNS, dengan jumlah frekuensi 5 dan persentase $11,1 \%, 3)$ Wiraswasta, dengan jumlah frekuensi 29 dan persentase $64,4 \%$, 4) Mengurus rumah tangga/tidak bekerja, dengan jumlah frekuensi 8 dan persentase $17,8 \%$. Berdasarkan data ini, hubungan pekerjaan dengan risiko PTSD dapat diketahui dengan mayoritas pekerjaam wiraswasta/swasta berjumlah 29 orang $(64,4 \%)(15)$. Hasil penelitian yang dilakukan Fontalba-Navas et.al., (2017) juga menunjukkan tidak ada hubungan antara pekerjaan dengan kejadian PTSD dimana ibu rumah tangga ( $p$ value $=0,91$ ), tidak bekerja ( $p$ value $=0,92)$, pensiunan $(p$ value $=0,27)$, dan wiraswasta $(\rho \text { value }=0,23)^{(12)}$.

Pada variabel dukungan sosial (dukungan teman, dukungan keluarga, dukungan relawan dan dukungan agama) menunjukkan bahwa tidak ada hubungan yang signifikan terhadap risiko kejadian PTSD pasca banjir. Hal ini bisa disebabkan karena jumlah sampel yang sedikit. Berbeda dengan penelitian Asim, Mohammad et, al (2019) yang menunjukkan bahwa faktor risiko kejadian PTSD di India terutama dipengaruhi oleh keragaman etnis, tingkat keparahan dan jenis kejadian banjir dan tidak adanya dukungan sosial ${ }^{(9)}$. Penelitian yang dilakukan di Hunan, China juga menunjukkan bahwa dukungan sosial yang rendah merupakan faktor risiko Kejadian PTSD (14).

\section{SIMPULAN DAN SARAN}

Kesimpulan 
Variabel jenis kelamin usia, pekerjaan, dan dukungan sosial diketahui tidak memiliki hubungan dengan risiko Kejadian hubunPTSD pascabanjir Jakarta dan Bekasi tahun 2020.

\section{SARAN}

Perlu dilakukan penelitian lanjutan dengan jumlah sampel yang lebih besar. Perlu dilakukan skrining PTSD segera setelah bencana terjadi sehingga bisa dilakukan upaya pencegahan PTSD sedini mungkin. Memberikan informasi kepada pembuat kebijakan terkait prevalensi kejadian PTSD pasca bencana.

\section{AUTHORS' CONTRIBUTION}

Penelitian ini dilakukan atas kerjasama empat penulis yaitu TF, NF, MN, dan TKA. Penulis TF mengerjakan desain penelitian, hasil penelitian dan pembahasan. Penulis NF menulis draf awal naskah. Penulis TF, MN dan TKA bekerjasama dalam mengelola analisis data, mengelola literatur. Keempat penulis telah membaca dan menyetujui draft akhir.

\section{FUNDING}

Penelitian ini didanai oleh Lembaga Penelitian dan Pengabdian Masyarakat (LPPM) Universitas Muhammadiyah Jakarta.

\section{ETHICS STATEMENT}

Penelitian ini sudah melalui kaji etik Reg No:915/KEPK-POLKEMA/2020.

\section{AVAILABILITY OF DATA}

Semua data yang relevan dan informasi pendukung sudah disertakan dalam artikel.

\section{CONFLICT OF INTEREST}

Semua penulis menyatakan bahwa tidak ada konflik kepentingan dalam penelitian ini dan penelitian dilakukan sesuai dengan kode etik yang berlaku.

\section{DAFTAR PUSTAKA}

1. Asep Koswara, Avianto Amri, Faisal Khalid Zainuddin, Ida Ngurah, Jamjam Muzaki, Lilis Muttmainnah, Maulinna Utaminingsih, Saul R.J Saleky, Widowati YT. Pendidikan Tangguh Bencana "Mewujudkan Satuan Pendidikan Aman Bencana di Indonesia." Jakarta; 2019.

2. Agus Wibowo. UPDATE: Rekapitulasi Data Bencana di Indonesia per 21 Januari 2020. Kepala Pusat Data Informasi dan Komunikasi Kebencanaan BNPB. 2020.

3. Khoirun Nisa. Rekapitulasi Data Banjir DKI Jakarta dan Penanggulangannya Tahun 2020. UNIT PENGELOLA STATISTIK DINAS KOMUNIKASI, INFORMATIKA DAN STATISTIK. 2020.

4. Rachmat Taufiq, Eka Susanty, Dyah Titi S EN. Gambaran Resiliansi Anak Pasca Bencana Banjir di Desa Dayeuhkolot, Kabupaten Bandung, Jawa Barat. Wacana J Psikol. 2014;6(11):73-87.

5. WHO. Bulding Back Batter:Sustainable Mental Health Care After Emergencies. Genewa: WHO Press; 2013.

6. Cesar A Alfonso. PTSD and Suicide After Natural Disasters. Psychaitric Times. 2018.

7. Stanke C, Murray V, Amlôt R, Nurse J, Williams R. The effects of flooding on mental health: Outcomes and 
recommendations from a review of the literature. PLoS Curr. 2012;1-17.

8. Erlin F, Sari IY. Gejala PTSD (Post Traumatic Stress Disorder) Akibat Bencana Banjir Pada Masyarakat Kelurahan Meranti Rumbai Pesisir Pekanbaru. Din Lingkung Indones. 2020;7(1):17.

9. Asim M, Mekkodathil A, Sathian B, Elayedath R, N RK, Simkhada P, et al. Post-Traumatic Stress Disorder among the Flood Affected Population in Indian Subcontinent. Nepal J Epidemiol. 2019;9(1):755-8.

10. Reza Imaduddin RM, Traumatic P. Post Traumatic Stress Disorder Pada Korban Bencana Post Traumatic Stress Disorder in Disaster Victims. Stress Disord Disaster Vict [Internet]. 2019;10(2):178-82. Available from: https://akpersandikarsa.e-journal.id/JIKSH

11. Endiyono E, Hidayah NI. Gambaran Post Traumatic Stress Disorder Korban Bencana Tanah Longsor di Dusun Jemblung Kabupaten Banjarnegara.
Medisains. 2019;16(3):127.

12. Fontalba-navas A, Lucas-borja ME, Gilaguilar V, Arrebola JP. Incidence and risk factors for post-traumatic stress disorder in a population affected by a severe flood. Public Health. 2016;144:96-102.

13. Wani MARSRP. Post Traumatic Stress Disorder (PTSD) among Flood Victims in Kashmir Valley. EC Psychol Psychiatry. 2016;5:164-70.

14. Dai W, Chen L, Tan H, Wang J, Lai Z, Kaminga AC, et al. Association between social support and recovery from posttraumatic stress disorder after flood: A 1314 year follow-up study in Hunan, China Chronic Disease epidemiology. BMC Public Health [Internet]. 2016;16(1):1-9. Available from: http://dx.doi.org/10.1186/s12889-0162871-x

15. Surwaningsih, Muhafilah I, Herawati TM. Perubahan Kondisi Psikososial Dan Spiritual Pada Korban Ptsd ( Post Traumatic Stress Disorder ). J IImu Kesehat. 2019;11(1):1-11. 